\title{
Memória organizacional e o processo de gestão do conhecimento da Cooperativa de Trabalho de Catadores Unidos pela Natureza ${ }^{1}$
}

\author{
Louise de Lira Roedel Botelho ${ }^{2}$ \\ Paola Vogt ${ }^{3}$ \\ Fabiano Kapelinski ${ }^{4}$ \\ Eduardo Alex Karnikowski ${ }^{5}$ \\ Carolina Back Olegário ${ }^{6}$ \\ Graciele Machado Eberhardt ${ }^{7}$
}

\begin{abstract}
Resumo
O estudo aborda sobre a importância de se ter um resgate da memória organizacional no contexto da Cooperativa de Trabalho de Catadores Unidos Pela Natureza (COOPERCAUN) junto aos sócios cooperados e a Universidade Federal da Fronteira Sul (UFFS), onde por meio das ações e registros busca-se compreender a atuação da UFFS e seu impacto direto na vida e transformação social dos sócios cooperados da COOPERCAUN, através do uso da Memória Organizacional deste empreendimento de economia solidária. Sendo assim, por meio de uma pesquisa qualitativa e do uso da análise documental, propõe destacar os pontos chaves da Cooperativa junto à comunidade, bem como elementos importantes da sua formalização e continuidade. Para isso, serão realizados registros através de filmagens, fotografias e entrevistas. Tais registros têm como meta a construção e materialização de acontecimentos e marcos históricos importantes ao longo da formação e trajetória da Cooperativa, resultando em um acervo que permitirá um melhor entendimento sobre o fenômeno, a transformação da vida desses cooperados e a atuação da extensão universitária.
\end{abstract}

Palavras-chave: Memória organizacional. Tríplice hélice. Extensão universitária.

\section{Organizational memory and the knowledge management process of the Cooperativa de Trabalho de Catadores Unidos pela Natureza}

\begin{abstract}
The study addresses the importance of having a rescue of the organizational memory in the context of the Workers' Cooperative United by Nature (COOPERCAUN) with the cooperative members and the Federal University of the Southern Frontier (UFFS), where through actions and records we seek to understand the role of UFFS and its direct

\footnotetext{
${ }^{1} \mathrm{O}$ artigo contempla resultados do projeto de cultura “Memória organizacional: construindo identidades através da contação de histórias de vida no trabalho de catadores de materiais recicláveis do município de Cerro Largo/RS", aprovado no Edital 725/GR/UFFS/2019, da Universidade Federal da Fronteira Sul (UFFS).
}

2 Pós-Doutorado em Engenharia e Gestão do Conhecimento (UFSC). Professora do Programa de Pós-Graduação em Desenvolvimento e Políticas Públicas da Universidade Federal da Fronteira Sul (UFFS), campus Cerro Largo/RS.

E-mail: louisebotelho@gmail.com

${ }^{3}$ Acadêmica do Curso de Administração da Universidade Federal da Fronteira Sul (UFFS), campus Cerro Largo/RS. E-mail: vogtpaola00@gmail.com

${ }^{4}$ Mestrando do Programa de Pós-Graduação em Desenvolvimento e Políticas Públicas da Universidade Federal da Fronteira Sul (UFFS), campus Cerro Largo/RS. Bolsista CAPES. E-mail: fabianokapelinski@hotmail.com

${ }^{5}$ Acadêmico do Curso de Administração da Universidade Federal da Fronteira Sul (UFFS), campus Cerro Largo/RS. E-mail: duduhaas@hotmail.com

${ }^{6}$ Acadêmica do Curso de Administração da Universidade Federal da Fronteira Sul (UFFS), campus Cerro Largo/RS. E-mail: carolinnaback@gmail.com

${ }^{7}$ Acadêmica do Curso de Administração da Universidade Federal da Fronteira Sul (UFFS) campus Cerro Largo/RS. E-mail: gracimachado99@gmail.com
\end{abstract}


impact on the life and social transformation of COOPERCAUN's cooperative members, through the use of the Organizational Memory of this solidarity economy enterprise. Therefore, through qualitative research and the use of documentary analysis, it proposes to highlight the key points of the Cooperative with the community, as well as important elements of its formalization and continuity. For this, records will be made through filming, photographs and interviews. Such records aim at the construction and materialization of important historical events and milestones throughout the formation and trajectory of the Cooperative, resulting in a collection that will allow a better understanding of the phenomenon, the transformation of the lives of these members and the performance of university extension.

Keywords: Memory organizational. Triple helix. Extension university.

\section{Introdução}

A COOPERCAUN consiste em uma cooperativa de trabalho, onde por meio da organização conjunta, tem-se a criação de posto de trabalho quanto a coleta, triagem e reciclagem de resíduos sólidos. Situa-se na Linha Primeira, interior do município de Cerro Largo/RS e conta com vinte (20) sócios cooperados que tem sua renda proveniente da comercialização de materiais recicláveis oriundos da coleta seletiva de Cerro Largo/RS, bem como, da parceria firmada com o município vizinho de Rolador/RS, que destina os materiais para a COOPERCAUN. Tendo em vista o seu ramo de atuação ambos os municípios são impactados pelo exercício de sua atividade, visto que a coleta seletiva se mostra vital para a operacionalização das atividades de triagem de materiais (BOTELHO; KAPELINSKI; KARNIKOWSKI, 2019).

A cooperativa foi formalizada em dezembro de 2016 com o assessoramento da Universidade Federal da Fronteira Sul (UFFS) campus Cerro Largo/RS, inicialmente tiveram-se treze (13) sócios fundadores, sendo que a cooperativa se encontrava com sua sede administrativa na Rua Bernardo José Psiuk № 279, Bairro Espanada, Cerro Largo/RS. Por sua vez, a UFFS presta assessoria quanto às práticas e atividades extensionistas ligadas ao assessoramento gerencial da referida cooperativa. Neste sentido, são organizados cursos de capacitação nas diferentes áreas administrativas, bem como é realizado um acompanhamento minucioso de apresentação e discussão de práticas gerenciais (BOTELHO; KAPELINSKI; KARNIKOWSKI, 2019). Desse modo, visualizar e compreender a holística deste processo, conjuntamente, considerando o desenvolvimento pessoal, profissional e organizacional, tornase desafiador desde sua concepção mais básica.

Nesse ponto de vista o conhecimento mostra-se como um importante instrumento transformador do meio de vida das pessoas e organizações que atuam na sociedade, assim promovendo o desenvolvimento de diversas áreas e instituições. Deste modo, compreender como as organizações se comportam vem ao encontro de tal desenvolvimento. Neto (2008) 
propõe que o conceito de gerir e construir conhecimento vai além do gerenciamento de informações, passando a considerar aspectos pertinentes à sua concepção. A memória organizacional é um conceito que está dentro desse processo, sendo definido como uma "ferramenta" que leva ao compartilhamento e reutilização do conhecimento organizacional e pessoal (DE SÁ FREIRE et al., 2012).

No entanto, o projeto conta com os seguintes objetivos: Compreender a atuação da Universidade Federal da Fronteira Sul e seu impacto direto na vida e transformação social de Cooperados de uma Cooperativa de Trabalho de Catadores no município de Cerro Largo, por meio do uso da Memória Organizacional deste empreendimento de economia solidária; Registar acontecimentos, como uma forma de se criar uma memória, o qual poderá servir de subsídio a demais pesquisas que se seguirão; Preservar a história de vida e o trabalho dos catadores de materiais recicláveis no município de Cerro Largo e estruturar a linha de tempo da COOPERCAUN; além de; Demonstrar a importância da UFFS na construção de uma memória organizacional na COOPERCAUN como forma de se obter um arcabouço sobre os conhecimentos adquiridos durante essa caminhada. Todavia, com esse estudo propõem-se evidenciar a importância da memória organizacional para construir um acervo de informações da COOPERCAUN, apresentando possíveis resultados e a relação com a comunidade, provindos da extensão universitária.

\section{Referencial teórico}

Buscando proporcionar um melhor entendimento sobre o assunto abordado, o estudo reporta a relação da universidade e extensão universitária, a tríplice hélice e, por último, a memória organizacional.

\subsection{Universidade e extensão universitária}

Melo Neto (2002) aponta que o início da extensão universitária ocorreu com as universidades populares europeias dos últimos séculos, que objetivavam disseminar os conhecimentos técnicos a população. Foi a partir das experiências americanas que surgiram duas novas visões diferenciadas das europeias, a visão cooperativa ou rural e a universitária em geral, estas que tinham como ideia principal a prestação de serviços (MELO NETO, 2002). 
No Brasil, a universidade popular surgiu através da instalação da Universidade Livre de São Paulo, no ano de 1912, e recebeu influências do médico Eduardo Augusto Guimarães. Esta universidade trazia o aparecimento da universidade popular junto do ensino superior e definiu a primeira proposta de extensão no país, através de cursos de extensão, prática que foi difundida nacionalmente (SOUZA, 2005).

A ideia de universidade popular foi retomada no país a partir da década de 30, e com isso, ocorreu uma movimentação em experiências de práticas educativas de extensão, como por exemplo, salas de leitura, solução de problemas sociais, cursos para discussão, experiências de rádio e difusão cultural. A partir de então, a extensão universitária passou a fazer uma permuta entre a universidade e os saberes populares, o que gerou a transformação da sociedade e a sua relação com o ensino e pesquisa (SERRANO, 2013).

Na universidade, a extensão como função acadêmica, deve se integrar a outros dois pilares: o ensino e a pesquisa. O princípio da indissociabilidade das atividades de ensino, pesquisa e extensão é fundamental na formação acadêmica, pois a relação entre esses três pilares, quando bem articulados, traz mudanças significativas nos processos de aprendizagem, melhorando a formação dos estudantes e trazendo significativas contribuições aos professores que repassam este conhecimento. A pesquisa e a extensão, integrados ao ensino, com a universidade e com a sociedade, possibilita a melhoria da relação da teoria e prática, compartilhando o saber acadêmico com a sociedade e recebendo-o de volta, testado e reelaborado (DIAS, 2012).

Segundo Nogueira (2013), a universidade tem a extensão como um instrumento para cumprir a sua função social, e através dessa, é possível democratizar o conhecimento produzido e ensinado na universidade. Uma forma de possibilitar que a universidade atenda às demandas mais urgentes da população, promovendo assim, a reconstrução de uma sociedade mais justa.

\begin{abstract}
As instituições de ensino superior desempenham um papel estratégico para treinamento, desenvolvimento, transferência e adaptação profissional do conhecimento técnico-científico aos requisitos e necessidades da sociedade. A universidade através da extensão universitária cumpre uma tarefa crucial que se expressa no conjunto de ações que servem como eixo dinâmico para avanços científicos e tecnológicos em seu contexto social, econômico, político e cultural. A importância da extensão é permitir universidades em contato permanente com sua comunidade de influência, contribuindo para a solução de seus problemas, bem como para a satisfação de suas necessidades em correspondência com suas necessidades (GÁMEZ, 2015, p. 112).
\end{abstract}

No tocante a Universidade Federal da Fronteira Sul (UFFS) tem como missão interiorizar o ensino universitário público e promover, por meio de suas áreas de atuação - ensino, pesquisa e extensão - um novo ciclo de desenvolvimento econômico e social para a região sul do Brasil, 
mais precisamente, na fronteira oeste dos Estados do Rio Grande do Sul, Santa Catarina e Paraná (BOTELHO; THIELE, 2015).

Neste sentido, UFFS, desde a sua concepção, tem definido como um dos princípios de sua atuação procurar desenvolver uma estreita relação com a sociedade. Isto significa avançar nas ações de extensão, promovendo uma integração entre os conhecimentos acadêmicos e os saberes populares. Esta orientação não pode ser neutra, ao contrário, deve se constituir numa proposta transformadora para os sujeitos e grupos envolvidos. Portanto, o compromisso da UFFS com o ensino, pesquisa e extensão é ímpar, sua preocupação está exposta inclusive em seus Projetos Políticos Pedagógicos (PPCs) e em seu Projeto Pedagógico Institucional (PPI) (BOTELHO; THIELE, 2015).

\title{
2.2 A relação da tríplice hélice
}

O termo Tríplice Hélice emergiu com a busca pela compreensão da relação universidade e governo, em meados dos anos 90, em estudos do pesquisador e professor universitário Henry Etzkowitz, da Universidade de Nova York (BOTELHO; THIELE, 2015). Para Etzkowitz e Zhou (2017, p. 24), a Tríplice Hélice é definida, como "um modelo de inovação em que a universidade/academia, a indústria e o governo, como esferas institucionais primárias, interagem para promover o desenvolvimento por meio da inovação e do empreendedorismo". Essas interações universidade-indústria-governo "são a chave para o crescimento econômico e o desenvolvimento social baseados no conhecimento" (ETZKOWITZ; ZHOU, 2017, p. 24).

Ainda segundo os autores, a Tríplice Hélice procura analisar os pontos fortes e fracos na esfera local e as "falhas" existentes que podem ser corrigidas por meio da articulação entre essas três esferas.

\begin{abstract}
Se até então as universidades possuíam um caráter exclusivamente educativo, nesta perspectiva atuam de forma mais interativa, promovendo ensino, pesquisa, e extensão e a propulsão de novos empreendimentos. Por meio de relações com os setores produtivos, a universidade toma conhecimento dos problemas, desafios e interesses econômicos direcionando seus esforços para contribuir com soluções para o desenvolvimento econômico regional e nacional. Entre os setores produtivos, destacam-se aqueles comprometidos com a economia solidária e tecnologias sociais (NUNES; PEREIRA; PINHO, 2017, p. 175).
\end{abstract}

Nesse sentido, o modelo sistemático abordado pela Tríplice Hélice, apresentado na Figura 1, baseia-se na atuação da universidade, sendo este considerado o ponto de partida para o desenvolvimento da relação entre indústrias e governo. A atuação da universidade possui como 
base a utilização dos conhecimentos provenientes dos processos estruturados do ensino, pesquisa e extensão (BOTELHO; THIELE, 2015).

Figura 1 - Modelo sistemático abordado pela Tríplice Hélice

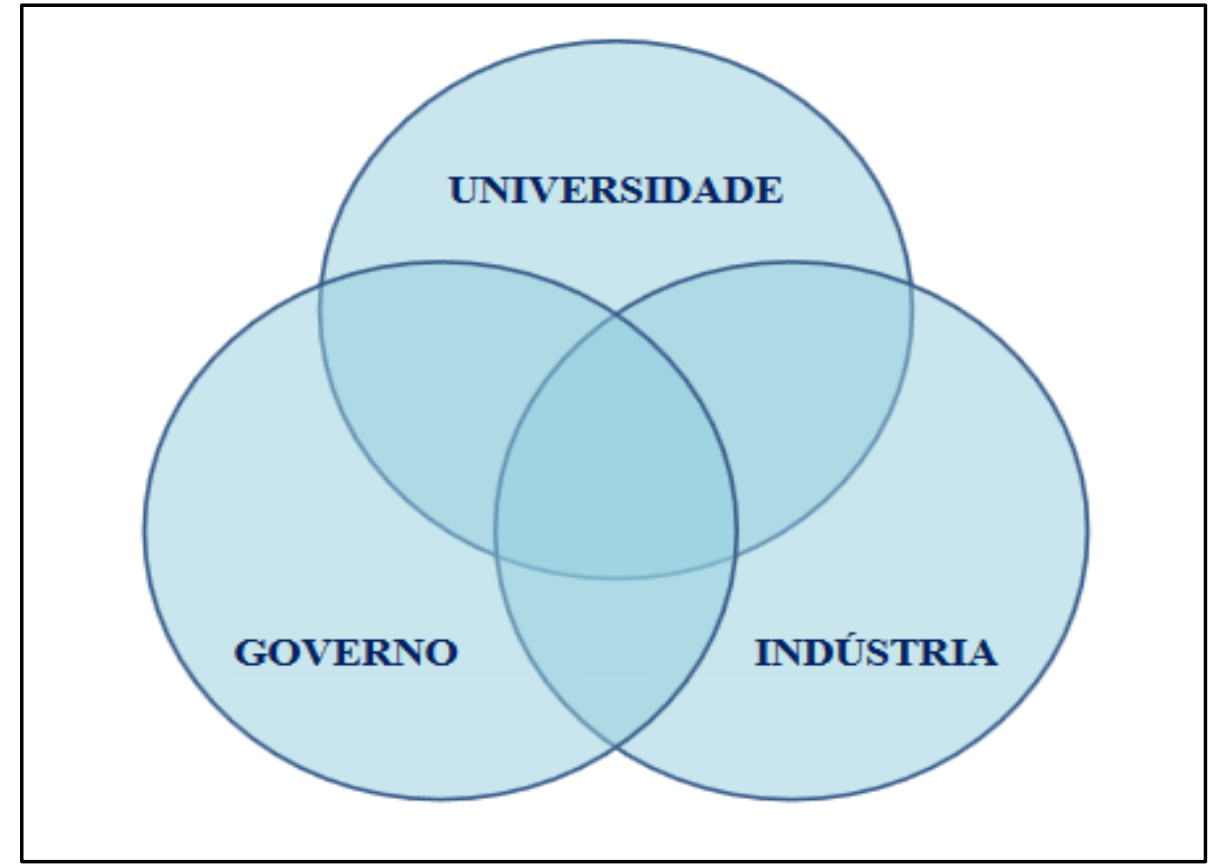

Fonte: Etzkowitz (2003), adaptado pelos autores.

O argumento da Tríplice Hélice estabelece que a universidade é capaz de exercer um papel preponderante na sociedade baseada no conhecimento (ETZKOWITZ; LEYDESDORFF, 2000). Esse argumento baseia-se na atuação conjunta da universidade e da sociedade na procura por melhorias em diferentes problemas sociais, tanto de origem intelectual quanto econômica e científica, pressupondo o reconhecimento e tratamento desses problemas por meio de um processo dinâmico que preconiza a pesquisa e o desenvolvimento como ferramenta de transformação social (ETZKOWITZ, 2009).

Essa interação tem a finalidade de produção de novos conhecimentos, possuindo o princípio de integração das experiências provenientes de ambos os campos de atuação que associam o modelo, objetivando a inovação tecnológica e o desenvolvimento econômico, pontos que incentivam as atividades dos setores público, privado e acadêmico visando um feedback às demandas sociais, como por exemplo emprego e geração de renda (BOTELHO; THIELE, 2015). De forma que a Tríplice Hélice torna-se relevante como forma de desenvolvimento nas diferentes delimitações territoriais, uma vez que, oportuniza a inovação e movimentação econômica através da maior interação entre os setores envolvidos (CHAIS, et al. 2013). 
Nesse sentido, a relação entre o governo, indústria e universidade é fundamental no que diz respeito às necessidades das pessoas, viabilizando crescentes melhorias nos diferentes aspectos do entorno social. Sendo assim, por meio da aproximação e comunicação entre estas diferentes esferas tem-se a capacidade de agregar diversos recursos, avançando na relação institucional que impacta em poder contribuir para o desenvolvimento tecnológico, em seus diferentes sentidos (GOMES; PEREIRA, 2015).

Considera-se que a relação oportunizada pela Tríplice Hélice materializa-se como forma quase perfeita de garantir o empreendedorismo, bem como a inovação, fomentando pesquisas de forma prática e usual, proporcionando mecanismos institucionais dinâmicos que favorecem o aspecto empreendedor e inovador, onde venham a interagir e beneficiar a sociedade (ETZKOWITZ; ZHOU, 2017).

\subsection{Memória organizacional}

“A memória organizacional pode ser entendida como a habilidade das organizações para salvar, reter e fazer uso de informações do passado nas atividades atuais. É um elemento chave que permite que as organizações aprendam dos erros e acertos do passado" (MELGAR-SASIETA; BEPLER; PACHECO, 2011, p. 1). A Memória Organizacional é representada por um modelo idealizado por Nilakanta, Miller e Zhu (2006) explicando onde esta habita, pelo que é composta e como esta composição funciona no sistema geral da organização (Figura 2).

O motor do conhecimento é localizado no centro do modelo, assim, de acordo com a perspectiva de Nilakanta, Miller e Zhu (2006) ele auxilia na relação e suporte aos demais elementos. Condizente com a Figura 2 esta é composta por um elemento externo que são os arquivos digitais e impressos e cinco elementos internos constituídos pelo indivíduo, cultura, a colaboração do grupo, a estrutura e a ecologia da organização.

Deste modo são esclarecidos tais elementos internos do modelo onde, os indivíduos são aqueles que trabalham na organização e consequentemente tem habilidades e atribuições incorporadas ao seu inconsciente fundando a memória individual. A cultura é um processo que está sempre sujeito a modificações decorrentes de novas experiências já que algumas experiências do passado podem colaborar com decisões futuras, de modo que, a cultura seja uma armazenagem organizacional. 
Figura 2: Memória organizacional em um sistema do conhecimento organizacional

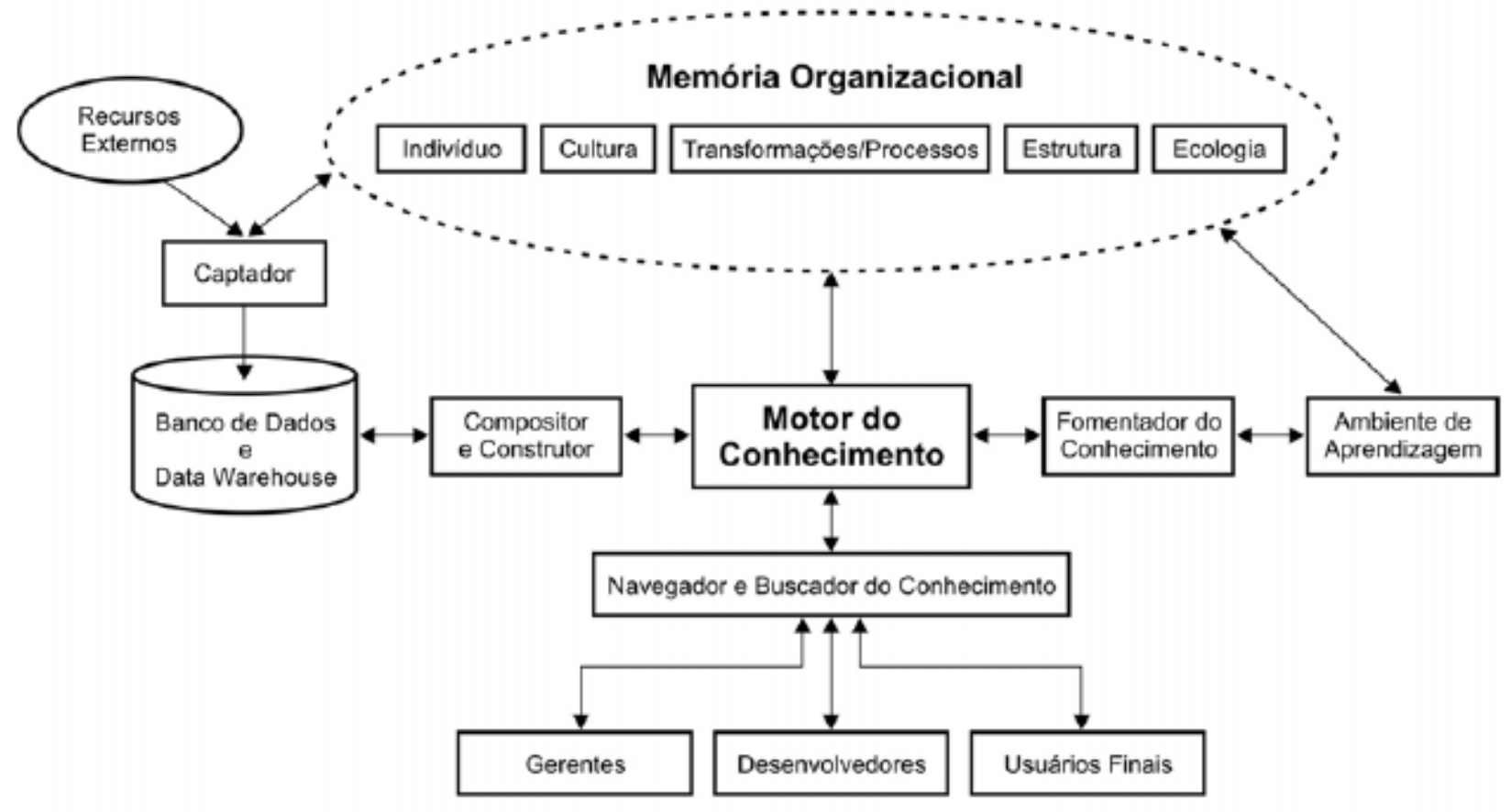

Fonte: Nilakanta, Miller e Zhu (2006, p. 88).

As colaborações do grupo é o conhecimento resultante das informações introduzidas nos processos que advém diariamente nas organizações. A estrutura atua entre o comportamento das pessoas e a relação desses indivíduos com o ambiente, os papéis individuais oferecem a conexão entre as memórias individuais e a organizacional. Já a ecologia do ambiente de trabalho codifica e apresenta informações, o aspecto físico da organização ajuda a delinear e aumentar as regras comportamentais (NILAKANTA; MILLER; ZHU, 2006). Além disso os autores destacam que a relevância dos elementos externos habita no fato de que a organização não é o único repositório de seu passado.

Deve-se ter a consciência de que a Memória Organizacional precisa responder as principais perguntas de uma organização relacionada ao ambiente, produtos, procedimentos e processos, concomitantemente deve funcionar como um serviço inteligente e ativo, onde consegue colocar à disposição de todos os funcionários da organização qualquer informação pretendida no mesmo momento ao qual foi solicitada (LASPISA, 2007).

Laspisa (2007, p.37) define Memória Organizacional (MO) como:

[...] conhecimento corporativo que representa experiências prévias que são arquivadas e compartilhadas pelos usuários. [...] constituída por um conhecimento explícito [...] e conhecimento tácito [...] e abrange aspectos funcionais, técnicos e sociais de trabalho, o trabalhador e o ambiente de trabalho. 
A Memória Organizacional deve ser verdadeira, para contribuir com o conhecimento. Sendo assim, toda universidade deve considerar a importância da MO, pois ela permite a capitalização, distribuição, utilização e troca de conhecimentos e recursos (LEBLANC; ABEL, 2007).

Portanto, a memória organizacional apresenta-se como ativo que possibilita minimizar a perda e o extravio de conhecimentos e gestão, uma vez que este elemento promove o apontamento de estratégias e ações para melhoria da gestão do conhecimento e da inovação da organização, de forma a evidenciar a criação de técnicas, métodos e uso de ferramentas que convertam o tácito em explícito (SHIRADO, 2017).

\section{Metodologia}

A pesquisa classifica-se quanto à abordagem em qualitativa, a qual está voltada à produção de dados descritivos, por meio das informações apresentadas pelos investigados e da conduta observada. Consiste, sim, em interpretar e compreender, com base em um olhar imparcial do pesquisador, a totalidade do ambiente em que se apresenta o objeto de estudo (TAYLOR; BOGDAN, 1998).

Quanto à natureza classifica-se em uma pesquisa básica, pois objetiva gerar conhecimentos novos, úteis para o avanço da Ciência, sem aplicação prática prevista, bem como envolve verdades e interesses universais. No que se refere aos objetivos trata-se de uma pesquisa descritiva, pois se busca compreender a atuação da Universidade Federal da Fronteira Sul e seu impacto direto na vida e transformação social de Cooperados de uma Cooperativa de Trabalho de Catadores no município de Cerro Largo/RS, através do uso da Memória Organizacional deste empreendimento de economia solidária.

No que diz respeito aos procedimentos classifica-se em uma pesquisa bibliográfica e documental. Já a coleta de dados será por meio de dados secundários obtidos por meio de relatórios e documentos da COOPERCAUN. Desse modo, o público-alvo são os catadores de materiais recicláveis da COOPERACUN, em que conta com 20 famílias beneficiadas com implantação da Cooperativa. Enquanto o universo consiste em ser o município de Cerro Largo/RS, em que conta com aproximadamente em 14.000 habitantes (IBGE, 2012).

Portanto este estudo adotará a perspectiva interpretativista com abordagem qualitativa, já que objetiva realizar os registros a partir da visão dos envolvidos no processo (cooperados), 
em sintonia com o método de abordagem indutivo, sendo necessário para sua concepção a revisão bibliográfica e a análise documental como principais técnicas de coleta de dados, somada à observação das práticas sociais, políticas e ambientais no território em questão.

\section{Análise e resultados}

A memória organizacional é composta de conhecimentos específicos e tácitos, que são diretamente ligados às pessoas que compõem determinada organização, sendo fundamental a sua socialização e discussão (DE SÁ FREIRE et al., 2012). Os acervos tangíveis da memória organizacional perpassam diferentes tipificações, consagrando-se por facilitar a compreensão do contexto organizacional, por meio das experiências armazenadas e conhecimento produzido (PEREIRA, 2013). Diante disso, registrar as atividades da COOPERCAUN vinculadas à extensão universitária, configura-se de modo a permitir maior exploração dos acontecimentos e conhecimentos transmitidos.

Como resultados pretende-se confeccionar a produção de documentários cujo principal objetivo é compreender e apresentar os avanços e mudanças em face de uma cooperativa de catadores, por meio de sua memória organizacional. Neste sentido, serão realizados registros através de filmagens, fotografias e entrevistas. Tais registros têm como meta a construção e materialização de acontecimentos e marcos históricos importantes ao longo da formação e trajetória da COOPERCAUN, considerando sua relevância no contexto socioambiental.

Nessa perspectiva, Batista (2012) ressalta a memória organizacional como sendo aquilo que indica o registro do conhecimento organizacional sobre processos, produtos, serviços e relacionamento com as pessoas. Vindo a esse encontro o estudo vem justamente proporcionar contribuições de gestão de conhecimento da COOPERCAUN, por meio da realização de um levantamento histórico de todo o seu processo, formalização, gestão, desenvolvimento e seus resultados até o momento, viabilizando o planejamento de ações para a sua própria consolidação.

Em vista disso, espera-se contribuir para a compreensão dos fenômenos decorrentes da formação e trajetória da COOPERCAUN, viabilizando construir uma narrativa história contendo os aspectos marcantes neste processo, permitindo que os cidadãos cerro-larguenses tenham maior entendimento sobre a função social de uma cooperativa de catadores. Além disso, o trabalho auxiliará na compreensão dos cooperados da COOPERCAUN sobre sua importância na 
sociedade, principalmente no munícipio de Cerro Largo, uma vez que se busca dar continuidade aos trabalhos realizados pelos docentes, técnicos e alunos que atuam na UFFS.

Por outro lado, com o intuito de captar e registrar os fenômenos decorrentes da atividade da COOPERCAUN motiva-se os grupos artísticos locais, onde através de imagens e relatos da condição humana básica de expressar seus sentimentos, emoções, ideias, através de figuras, cores e formas desenvolvem suas atividades, destacando o potencial cognitivo da imagem que permite inseri-la no conjunto de mediadores culturais participantes do processo de construção do conhecimento sobre a vida e o trabalho cooperativo, servindo de "insumo cultural", fomentando tais grupos. Ainda, dar continuidade aos novos projetos significa também maior visibilidade da causa, deste modo permitindo replicar e/ou adaptar ações em outros municípios.

Em contrapartida, possibilitará a aproximação da comunidade cerro-larguense com a Universidade Federal da Fronteira Sul, voltando-se para as transformações sociais que ocorrem neste município, evidenciando as particularidades culturais, tendo como base a cooperação, a sustentabilidade e a transformação social, colocando a UFFS como entidade motora do desenvolvimento regional sustentável. Sendo que, pretende-se com isso, construir registros que favorecem a compreensão do contexto da COOPERCAUN, demonstrando o comprometimento e o impacto que uma Universidade Pública traz para a sociedade, de modo a construir soluções para o bem comum.

Em vista das transformações sociais vale ressaltar a mudança na vida dos sócios cooperados da COOPERCAUN no sentido de geração e incremento de trabalho e renda, visto que pela quantidade e processamento do material, este possui maior valor agregado na sua comercialização. De igual forma, destaca-se a emancipação social, onde com o trabalho organizado e em conjunto, se ganha visibilidade no contexto em que a cooperativa está inserida. Não menos importante, o aspecto ambiental também é impactado positivamente, uma vez que maior quantidade de resíduos volta a cadeia produtiva, aumentando a vida útil do aterro sanitário, além disso, tem-se a economicidade com gastos por parte do município de Cerro Largo/RS, no transporte e destinação de resíduos ao aterro.

Quanto à extensão universitária cabe ressaltar que o assessoramento e convívio entre professores, técnicos-administrativos, estudantes e sócios cooperados resulta em uma experiência inédita. Portanto os estudantes têm a possibilidade de aplicação prática dos ensinamentos adquiridos em sala de aula, permitindo-os conhecer uma realidade diferente daquelas que tradicionalmente são abordadas. Do mesmo modo, a COOPERCAUN, em sua gestão conta com assessoria e suporte técnico, neste caso quanto às diferentes áreas da administração 
do negócio, de tal forma que os registros tidos por meio de relatórios e afins permitem visualizar o empreendimento de modo diferenciado, em relação às visitas periódicas, possibilitando uma análise profunda ao somar as diferentes documentações.

Portanto, a construção de uma memória organizacional da COOPERCAUN, possibilitará visualizar e compreender de modo holístico todo o processo de formação e assessoramento técnico concedido, considerando o desenvolvimento pessoal, profissional e organizacional, o que demostra ser desafiador desde sua concepção mais básica. Diante disso, este estudo é importante do ponto de vista, cultural e sustentável porque permitirá a valorização da COOPERCAUN, composta por catadores de materiais recicláveis e reutilizáveis, cujo contexto em que se encontra permite desenvolvimento ambiental, social e econômico. Ambiental porque retira materiais recicláveis das vias e logradouros públicos; Social porque estimula a formação de cooperativa com princípios de Economia Solidária e Cooperativismo; e Econômico porque gera trabalho e renda para os sócios cooperados.

\section{Considerações finais}

Considerando que a memória organizacional constitui-se como fator histórico, logo inserido em um espaço de tempo, propõem-se alcançar os objetivos, a fim de apresentar posteriormente os acontecimentos, permitindo construir um acervo com informações importantes no acompanhamento da COOPERCAUN, como também tornando cada vez mais sólida a sua relevância no contexto social através da geração de trabalho e renda para o município de Cerro Largo/RS. Salienta-se que, mesmo que a história da cooperativa de trabalho seja relativamente curta, faz todo sentido construir e manter um acervo com os acontecimentos considerados importantes, o que nos leva a aprofundar nossas análises de compreensão, tanto em decisões estritamente gerenciais, como também em de maior complexidade.

Apresenta-se como ganho acadêmico a aproximação da universidade com a comunidade local, além disso, como meio de transformação social pelo fato de gerar emprego e renda. Tal conjuntura mostra-se claramente como um exemplo prático de desenvolvimento regional sustentável, servindo de inspiração para outras localidades a fim de reproduzir estes conceitos, a memória organizacional, auxilia justamente neste processo. 


\section{Referências}

BATISTA, Fábio Ferreira. Modelo de Gestão do Conhecimento para a Administração Pública Brasileira: Como implementar a Gestão do Conhecimento para produzir resultados em benefício do cidadão. Rio de Janeiro: Ipea, 2012. 134 p. Disponível em:

<http://www.gespublica.gov.br/sites/default/files/documentos/modelo_de_gestao_do_conhe cimento_para_a_administracao_publica_brasileira._livro.pdf>. Acesso em: 31 jul. 2019.

BOTELHO, Louise de Lira Roedel; THIELE, Jéssica. Reflexões sobre o papel das universidades empreendedoras e os desafios do estabelecimento de incubadoras tecnossociais: Universidades Empreendedoras e a Tríplice Hélice. In: NOGUEIRA, Sandra Vidal et al (Org.). Educação popular, democracia e direitos humanos: ensaios para uma pedagogia universitária interdisciplinar e transversal. ljuí: Unijuí, 2015. p. 131-133.

BOTELHO, Louise de Lira Roedel; KAPELINSKI, Fabiano; KARNIKOWSKI, Eduardo Alex. Memória Organizacional da Cooperativa de Trabalho de Catadores Unidos pela Natureza. $37^{\circ}$ Seminário de Extensão Universitária da Região Sul. 2019. Disponível em:

$<$ https://scholar.google.com.br/scholar?hl=pt-

PT\&as_sdt=0\%2C5\&q=MEM\%C3\%93RIA+ORGANIZACIONAL+DA+COOPERATIVA+DE+TRABALHO +DECATADORES+UNIDOS+PELA+NATUREZA\&btnG. Acesso em: 25 out. 2019.

CHAIS, Cassiane et al. Atuação dos núcleos de inovação tecnológica na promoção do desenvolvimento regional a partir da abordagem da tríplice hélice. Gestão Universitária na América Latina (GUAL), Santa Catarina, Brasil, v. 6, n. 4, p. 171-189, nov./2013. Disponível em: <http://www.redalyc.org/articulo.oa?id=319329765011>. Acesso em: 30 jul. 2019.

DE SÁ FREIRE, Patrícia et al. Memória organizacional e seu papel na gestão do conhecimento. Revista de Ciências da Administração, Florianópolis, v. 14, n. 33, ago. 2012. Disponível em: < https://periodicos.ufsc.br/index.php/adm/article/view/25324>. Acesso em: 15 de jul. 2019.

DIAS, Ana Maria lorio. Pesquisa na graduação e na práxis docente: educação para emancipação humana. In: BEZERRA, T. S. A. M.; CAVALCANTE, L. M.; FRANCO, R. K. G.; SAMPAIO, L. M. P. A pesquisa na graduação: emancipação humana, práxis docente, trabalho e educação. Campina Grande: Realize Editora, 2012.

ETZKOWITZ, Henry; ZHOU, Chunyan. Hélice tríplice: inovação e empreendedorismo universidade-indústria-governo. Estudos Avançados, São Paulo, v. 31, n. 90, p. 23-48, maio/ago. 2017. Disponível em:

http://www.scielo.br/scielo.php?script=sci_arttext\&pid=S0103-40142017000200023. Acesso em: 17 jul. 2019.

ETZKOWITZ, Henry. Innovation in Innovation: The Triple Helix of University-IndustryGovernment Relations. Social Science Information, Paris, v. 42, n. 3, p. 293-337, 2003.

ETZKOWITZ, Henry; LEYDESDORFF, Loet. A dinâmica de inovação: de sistemas Nacionais e "Modo 2" a hélice tripla de relações-indústria-governo da universidade. Policy Research, v. 29, n. 2, p. 109-123, 2000.

ETZKOWITZ, Henry. Hélice Tríplice: Universidade-Indústria-Governo-Inovação em Movimento. Porto Alegre: EDIPUCRS, 2009.

GAMEZ, Fremiot. La dimensión social: un proceso sinérgico en la interacción universidadcomunidad a través de la función de extensión. Investigación y Postgrado, Caracas, v. 30, n. 1, p. 103-123, abr. 2015. Disponível em: 
$<$ http://ve.scielo.org/scielo.php?script=sci_arttext\&pid=S1316-

00872015000100006\&lng=es\&nrm=iso>. Acesso em: 14 jul. 2020.

GERHARDT, Tatiana Engel; SILVEIRA, Denise Tolfo. Métodos de pesquisa. 1. ed. Porto Alegre: UFERGS-Editora, 2009. Disponível em:

<https://books.google.com.br/books?id=dRuzRyElzmkC\&printsec=frontcover\&dq=M\%C3\%A9to dos+de+pesquisa\&hl=pt-

BR\&sa $=X \& v e d=0$ ahUKEwisneKStt3MAhVFh5AKHcQmD80Q6AEIHDAA\#v=onepage\&q=M\%C3\%A 9todos\%20de\%20pesquisa\&f=false>. Acesso em: 06 mai. 2019.

GOMES, Myller Augusto Santos; PEREIRA, Fernando Eduardo Canziani. Hélice tríplice: um ensaio teórico sobre a relação universidade-empresa-governo em busca da inovação. International Journal of Knowledge Engineering and Management, Florianópolis, Brasil, v. 4, n. 8, p. 136-155, jun./2015. Disponível em:

<http://stat.ijkem.incubadora.ufsc.br/index.php/IJKEM/article/view/3309>. Acesso em: 31 jul. 2019.

IBGE (Instituto Brasileiro de Geografia e Estatística. Censo Demográfico 2010: Características da população e dos domicílios: resultados do universo. Rio de Janeiro: IBGE; 2012.

LASPISA, David Frederick. Influência do conhecimento individual na memória organizacional: um estudo em call centers. 2007. 121 f. Dissertação (Mestrado em Engenharia e Gestão do Conhecimento) - Programa de Pós-Graduação em Engenharia e Gestão do conhecimento, Universidade Federal de Santa Catarina, Florianópolis, 2007. Disponível em:

<https://repositorio.ufsc.br/xmlui/handle/123456789/90669?show=full>. Acesso em: 27 jun. 2019.

LEBLANC, Adeline; ABEL, Marie-Hélène. Using organizational memory and forum in an organizational learning context. 2007. Disponível em:

http://ieeexplore.ieee.org/stamp/stamp.jsp?tp=\&arnumber=4444234. Acesso em: 27 jun. 2019.

NETO, Rivadavia Correa Drummond De Alvarenga. Gestão do conhecimento em organizações: proposta de mapeamento conceitual integrativo. 1 ed. São Paulo: Saraiva, 2008. 328 p.

Disponível em:

$<$ https://books.google.com.br/books?id=DyprDwAAQBAJ\&printsec=frontcover\&hl=ptBR\&source=gbs_ge_summary_r\&cad=0\#v=onepage\&q\&f=false>. Acesso em: 06 mai. 2019.

NILAKANTA, Sree; MILLER, L. L.; ZHU, Dan. Organizational memory management: technological and research issues. Journal of Database Management, Pennsylvania, v. 17, n. 1, p. 85-94, jan./mar. 2006. Disponível

em:<https://www.researchgate.net/publication/220373721_Organizational_Memory_Manage ment_Technological_and_Research_Issues >. Acesso em: 17 jul. 2019.

NOGUEIRA, Maria das Dores Pimentel. O Fórum de Pró-reitores de Extensão das Universidades Públicas Brasileiras: um ator social em construção. Interfaces - Revista de Extensão, v. 1, n. 1, p. 35-47, 2013.

NUNES, Enedina Betânia Leite de Lucena Pires; PEREIRA, Isabel Cristina Auler; PINHO, Maria José de. A responsabilidade social universitária e a avaliação institucional: reflexões iniciais. Avaliação. Campinas; Sorocaba, São Paulo. v. 22, n. 1. p. 165-177, 2017.

MELO NETO, José Francisco. Extensão universitária: bases ontológicas. MELO NETO, J. F. (Org.). Extensão universitária: diálogos populares. 1. ed. João Pessoa: Editora da Universidade Federal da Paraíba, 2002. 
PEREIRA, Claudio de Souza. Memória Organizacional: conceito e práticas em construção. Encontro da ANPAD, Rio de Janeiro, v. 37, p. 01-15, set. 2013. Disponível em:

$<$ http://www.anpad.org.br/ anpad/eventos.php?cod_evento=1\&cod_edicao_subsecao=966\&c od_evento_edicao=68\&cod_edicao_trabalho=15641>. Acesso em: 30 de jul. 2019.

SASIETA, Héctor Andrés Melgar; BEPPLER, Fabiano Duarte; PACHECO, R. C. D. S. A memória organizacional no contexto da engenharia do conhecimento. DataGramaZero-Revista de Informação, v. 12, n. 3, 2011.

SERRANO, R. M. S. M. Conceitos de extensão universitária: um diálogo com Paulo Freire. Grupo de Pesquisa em Extensão Popular, v. 13, n. 8, 2013.

SOUZA, O. S. S. A extensão universitária e as universidades populares. Revista FACED, n.9, p.253-264, 2005.

SHIRADO, Yuri Luciana et al. Memória organizacional e sua contribuição no processo de gestão do conhecimento. Colóquio em Organização, Acesso e Apropriação da Informação e do Conhecimento. Londrina, 2017. Disponível em: <

http://www.uel.br/eventos/cinf/index.php/coaic2017/coaic2017/paper/view/505/340> Acesso em: 18 jul. 2019. 